\title{
Literatura como resistência ao genocídio cotidiano: os saraus realizados em Fortaleza, Ceará, 2014-2019
}

\author{
Literature as resistance to everyday genocide: the soirees held \\ in Fortaleza, Ceará, 2014-2019
}

Enviado em: 30/09/2020

Aceito em: 05/01/2021

Atilio Bergamini ${ }^{1}$

\section{Resumo}

Este ensaio procura compreender alguns traços da ideia de literatura criada por saraus e coletivos culturais que se constituíram desde pelo menos 2014 na cidade de Fortaleza, capital do Ceará, estado do Nordeste do Brasil. Para isso, delineia também as feições do que os integrantes desses coletivos denominam genocídio cotidiano. Enquanto, em parte da teoria da literatura acadêmica, o discurso literário seria aquele que "estranha" os discursos da vida cotidiana, na teoria da literatura dos coletivos culturais de Fortaleza, literatura seria o discurso que suspende o genocídio cotidiano.

Palavras-chave: literatura, saraus, genocídio

\begin{abstract}
This essay seeks to understand some features of the idea of literature created by soirees and cultural collectives that have been constituted since at least 2014 in the city of Fortaleza, capital of Ceará, state of Northeast Brazil. For this, it also outlines the features of what the members of these collectives call everyday genocide. While, in part of the theory of academic literature, the literary discourse would be the one that "strangers" the discourses of everyday life, in the theory of the literature of cultural collectives in Fortaleza, literature would be the discourse that suspends the daily genocide.
\end{abstract}

Keyword: literature, soirees, genocide

\section{Duas tarefas}

Sou professor de literatura em uma universidade pública na cidade de Fortaleza, situada no estado do Ceará, Nordeste do Brasil. ${ }^{2}$ Na minha profissão, ocupo-me um

1 - Professor do Departamento de Literatura da Universidade Federal do Ceará (UFC) e do Programa de Pós-Graduação em Letras da Universidade Federal do Ceará. Pesquisa narrativas de crimes contra a humanidade especialmente na América Latina. Também pesquisa Machado de Assis; ensino de literatura; e relações entre cultura letrada e escravidão. Coordena, na UFC, desde 2016, um grupo de estudos sobre Marxismo e Literatura. É formado em Letras pela Universidade Federal do Rio Grande do Sul e tem mestrado e doutorado pela mesma instituição, com pesquisas sobre a literatura de Machado de Assis na imprensa liberal. Durante o doutorado, fez estágio-sanduíche na Yale University. Atuou em pósdoutoramentona Universidade Estadual de Campinas, no projeto de pesquisa "Circulação Transatlântica dos Impressos". 
tanto em pensar quais textos literários propor para leitura dos estudantes que assistem minhas aulas, cerca de $80 \%$ dos quais oriundos de famílias com renda per capita menor do que um salário mínimo. Tento encontrar obras que possuem alguma permanência em tradições culturais diversas. Machado de Assis, por exemplo, foi lido e discutido desde o século XIX por positivistas, modernistas, cordelistas, feministas, marxistas, estruturalistas, liberais. Por isso, trago comigo a autojustificação talvez imaginária de que ler Machado em profundidade com os estudantes pode ajudá-los a se posicionar criticamente no conjunto da história das ideias. Ler Machado poderia dadas certas condições que não vem ao caso discutir neste ensaio - ser uma forma de nos emanciparmos das forças que nos prendem ao presente imediato da produção e do consumo de mercadorias.

Preocupo-me também com outro aspecto do problema: refiro-me aos escritores e às escritoras que as tradições esqueceram. Eu não teria, como professor de literatura, o papel de trazer para o debate em sala de aula ideias e formas que foram apagadas?

Assim, busco inserir nas aulas, além de autores "clássicos", também autores que pouco ou nada circulam; não deixa de ser um modo de entender melhor e de discutir os limites éticos e epistemológicos da disciplina que ministro. Por que tanta prevalência de autores europeus? Por que só ler os gêneros consagrados por certas tradições?

Entre os dois campos de reflexão, surgem obras cuja complexidade própria interessa em si mesma e também para colaborar na formação de professores de literatura, que é minha primeira função na universidade. Prestar atenção na literatura escrita ou falada na cidade onde vivo e onde dou aulas se torna, em meio a isso, uma das minhas preocupações. Pensando e vivendo essa literatura, sinto a necessidade de apresentá-la aos estudantes.

Tento dizer para eles, vejam como esta é uma literatura interessante, aguda, crítica, produzida por pessoas como vocês. Lembrem do jovem Marx, em seus entusiasmados humanismos de democrata radical, dizendo que a teoria pode se converter numa força material e revolucionária. ${ }^{3}$ Vocês percebem, como eu percebo, o

2 - Agradeço a Suene Honorato pelas leituras e comentários a diversas versões deste artigo. Também agradeço aos bolsistas de iniciação científica, Késsia Rodrigues e Gersilton Nobre, estudantes de graduação em Letras na Universidade Federal do Ceará, que fazem parte da construção em andamento destas ideias e problemas.

3 - A força material da teoria foi discutida por Marx no artigo "Crítica da filosofia do direito de Hegel introdução", publicado nos Anais franco-alemães, no início de 1844. Durante aquele ano, a concepção de que a teoria entraria nas massas dando-lhes potência revolucionária se inverteria dialeticamente: as 
quanto, nestas obras poéticas que estou trazendo, a poesia se transforma com grande potência numa força material? Ou estou enganado?

Ao me inserir cotidianamente nos movimentos da literatura produzida na cidade onde vivo e ensino e sentir nela essa potência radical, coloquei-me duas tarefas: a primeira é convidar constantemente escritores e escritoras para virem à universidade falar sobre suas obras, ao mesmo tempo em que convido estudantes para irem a bibliotecas comunitárias, saraus, lançamentos de livros e agitações promovidos por aqueles mesmos escritores e escritoras. A segunda tarefa é especular a respeito da literatura produzida na minha cidade, de maneira que eu possa, na impossibilidade de sempre contar em minhas aulas com a presença viva dos escritores e escritoras, falar a partir de suas obras com a devida preparação. O presente ensaio é uma forma de eu me instruir para esta segunda tarefa.

\section{Microfone aberto}

À semelhança do dispositivo analítico inventado por Freud (uma pessoa falando em associação livre, reclinada em um divã, sendo escutada, numa escuta flutuante, por um analista, havendo entre os dois um vínculo, a transferência), jovens artistas moradores das periferias de Fortaleza estão inventando um dispositivo artístico. Tratase do seguinte: em um espaço público - praça, esquina - jovens instalam uma caixa de som e um microfone; pessoas escutam aquilo que é dito ou performado no microfone: poesias, cantos, desabafos, discursos contra o Estado, contra a polícia e contra as facções, louvores da arte como resistência, dança e teatro. A ligação entre os participantes é, em geral, de solidariedade, incentivo e afeto. Todos são ao mesmo tempo artistas e espectadores. Em torno do microfone aberto, ficam algumas vezes poucas pessoas, outras vezes, como ocorreu em 02 de novembro de 2019, no bairro Jangurussu, aproximadamente $160 .^{4}$

Tendo em vista o objetivo geral deste ensaio, vou tentar a partir de agora discutir uma ideia recorrente em poemas apresentados em saraus de microfone aberto

massas agora se tornavam um "povo filosófico" criando a teoria-prática da emancipação humana. Para esse segundo momento, ver as "Glosas críticas ao artigo 'O rei da Prússia e a reforma social”, publicadas por Marx em agosto de 1844.

4 - Para uma análise cuidadosa dos saraus de Fortaleza, ver o trabalho de Rômulo Silva, Rede de afetos: práticas de re-existências poéticas na cidade de Fortaleza, Ceará (dissertação de mestrado), Universidade Estadual do Ceará, Fortaleza, 2019, disponível em http://www.uece.br/ppgsociologia/index.php/arquivos/doc view/847-?tmpl=component\&format=raw. 
promovidos por coletivos culturais nas periferias de Fortaleza. Essa ideia é organizada em duas partes: a juventude das periferias das cidades brasileiras está sendo vítima de um genocídio cotidiano, protagonizado pelo Estado e por facções (ou, se quisermos dizer de outro modo, pelos movimentos do tráfico internacional de drogas e armas); diante disso, a literatura se constitui uma prática de resistência. Genocídio cotidiano e literatura, portanto, são os dois núcleos de sentido que precisamos aprofundar.

\section{Literatura te tira do tiro}

Um poema muito repetido nos saraus foi produzido pelo poeta Jardson Remido. No passado, Remido foi abandonado pela escola, atuou no tráfico de drogas, foi preso, e superou o que chama de "mudez" inspirando-se nas letras de uma das grandes referências dos saraus, o rapper brasileiro Sabotage, assassinado em 2003, aos 30 anos: "Não tinha vontade de falar", afirma Remido, hoje com 26 anos, "e tive momentos de muita reflexão". 5

O poema de Remido que vou tomar como ponto de partida para esta discussão é composto por um único verso:

"Literatura te tira do tiro da viatura."

Além de ser repetido nos saraus, ele foi pichado em muros e é declamado por Remido em performances em ônibus de Fortaleza.

Do ponto de vista da teoria da literatura, o poema guarda sua eficácia em razão da complexa estrutura formal: as consoantes perfazem sons dentais e alveolares, isto é, interrompidos, mas vibrantes: "t"s e "d"s e "r"s. Tdrrrrr... Seria a onomatopéia das rajadas. Genocídio.

O verso se apresenta como que dividido em duas redondilhas maiores:

5 - Sobre Remido ver Karla Dunder, "É a literatura que te tira do tiro da viatura", em Conselho Regional de Biblioteconomia, CRB-8, disponível em: http://www.crb8.org.br/10653-2/. Mauro Mateus dos Santos, conhecido como Sabotage, lançou em vida um único álbum de estúdio, Rap É Compromisso! A canção que dá título ao álbum é muito querida dos participantes dos saraus, trazendo versos como "Ah, polícia, sai do pé", "O rap é compromisso, não é viagem".

6 - Parte dos poemas citados foram escutados nos saraus a que pude assistir ao longo de 2018 e 2019. Pouco a pouco, conforme os escutava serem repetidos nos saraus, os decorei e os cito aqui conforme me ficaram destas vivências. Para uma coletânea recente dos poemas produzidos em saraus de Fortaleza, cf. Azigon, Tales (org.), Ruma: poemas de saraus, Fortaleza: Governo do Estado do Ceará, Secult, 2019. $\mathrm{Na}$ ficha catalográfica, o nome de Talles está grafado incorretamente com um só "l". 
- Segunda redondilha: "Do/ ti/ ro/ da/ vi/ a/ tu/ ra".

Os acentos poéticos na primeira redondilha recaem em /tu/ e /ti/ (na quarta e sétima sílabas). Já na segunda redondilha, os acentos recaem em /ti/ e /tu/ (na segunda e sétima sílabas). A inversão das sílabas tônicas reforça a batida do rap: $t u$, ti, ti, tu, inclusive com uma síncopa.

A contradição entre "literatura" e "viatura", já explícita no nível semântico e pragmático, acaba sendo realizada também no nível fonético e melódico do poema. Cabe lembrar ainda que a redondilha maior é um verso popular, muito utilizado em todo o Nordeste brasileiro em cordéis e canções. Assim, uma ideia de literatura popular, coloquial, aberta, em praça pública, permanece presente no nível formal do poema, que, ao soldar ou juntar duas redondilhas também insinua uma ideia de disfarce, já que a literatura é passada adiante aparentando ser uma espécie de frase de rua, um provérbio, um conselho.

"Literatura" e "viatura" rimam, o que as coloca frente a frente na linha da poesia, separadas por uma rajada, como se fosse um duelo: tdrrr. A elisão do artigo que antecederia o substantivo "literatura" confere certo isolamento sintático-semântico à palavra, que, por assim dizer, convoca um tom de voz específico para a leitura da frase: o chamado "papo reto". Não se trata de dizer "a literatura", mas, sim, "literatura". Haveria então dois destinos para a segunda pessoa do singular, evocada no poema: ou ela toma literatura para si ou está na linha de tiro.

O verbo "tirar", conjugado na terceira pessoa do presente do indicativo, "tira", aproxima-se do paradigma de menções aos policiais, os tiras. Literatura transforma tira em finta, em drible ao tiro. Literatura é uma possibilidade, o tiro é uma certeza. Tirar-se do tiro demanda uma ação: literatura. A segunda pessoa, o você ou tu do poema, pode ser Alvo-objeto (do tiro) ou Escudo-sujeito (literatura). Literatura é criar resistência. Ela tira o "tu", que pode ser virtualmente qualquer ouvinte do poema, da área do genocídio cotidiano, fundando um novo território, em que a pessoa que tem o suposto destino de morte se constitui sujeito de palavra e autorrepresentação estética e política.

\section{Jangurussu}


Um dos mais duradouros e reconhecidos saraus de Fortaleza, o Sarau da B1, acontece na avenida Boulevard 1, bairro Jangurussu. Este bairro foi assim apresentado por uma manchete de jornal, em 2017: "Jangurussu é o bairro em que mais se morre em Fortaleza". ${ }^{7}$ Morre-se muito no Jangurussu onde vivem cerca de 50 mil pessoas. Ali, a mortalidade infantil é uma das mais altas da cidade e do país: em 2017 houve 42 mortes de crianças. No mesmo ano, 150 pessoas foram assassinadas no bairro, quase todas jovens negros; entre eles, quase $70 \%$ tinham abandonado ou sido abandonados pela escola. O Índice de Desenvolvimento Humano do Jangurussu é 0,172 , entre os mais baixos do planeta, enquanto o IDH dos bairros mais endinheirados de Fortaleza chega a 0,980, mais alto do que países como Suécia, Noruega e Dinamarca. ${ }^{8}$ A sensação de extrema injustiça e absoluto desamparo estruturados pela desigualdade está marcada nos poemas apresentados no Sarau da B1. Seus participantes procuram reforçar a ideia de uma "re(existência)", existência que resiste, resistência que existe. ${ }^{9}$

Nomear a contradição entre as imagens associadas ao IDH 0,980 e as imagens associadas ao IDH 0,172 é uma das forças materiais dos poemas criados em torno do microfone aberto da B1. SUVs ${ }^{10}$, apartamentos, cocaína, lavagem de dinheiro, ioga e paz se contrapõem a ônibus lotado, maconha, falta de dinheiro, desamparo e violência.

No rap "Admirável bixa louca", da poeta e rapper Madame Satã (ou apenas Má Dame), muito atuante em diversos saraus, que se apresenta como artista de "ocupações", a competição neoliberal fundamenta as mais exacerbadas formas de injustiça. Para abordar essa exacerbação da injustiça, Madame cria a imagem de uma rinha: "Tô traficando meus versos e eles vem com cocaína/(...) jogando meu rap no vento violento, pique de rinha". Nesse rap, quem fala se identifica como pessoa negra

7 - Ver NOGUEIRA, Adriano. "Jangurussu é o bairro onde mais se morre em Fortaleza". Em Jornal O Povo. Disponível em https://www.opovo.com.br/jornal/cotidiano/2017/10/jangurussu-e-o-bairro-onde-maisse-morre-em-fortaleza.html.

8 - Todos os dados utilizados neste parágrafo foram retirados do dossiê Cada vida importa: relatório final do Comitê Cearense pela Prevenção de Homicídios na Adolescência, de 2016. Alguns foram atualizados a partir do site do IBGE (https://www.ibge.gov.br/).

9 - Para um maior aprofundamento sobre "re(existência)", ver, de Geovani Jacó de Freitas e Rômulo Silva, "Práticas poéticas: juventude, violência e insegurança em Fortaleza", disponível na revista Tensões mundiais,https://revistas.uece.br/index.php/tensoesmundiais/article/view/887.

10 - SUV é sigla para Sport Utility Vehicle. São "carrões" grandes, caros e poluentes, muito utilizados pelas classes endinheiradas no Brasil, que, não raro, os compra blindados. Em um dos poemas declamados num dos saraus em 2019, esses carros aparecem relacionados a tanques de guerra. 
e bicha (isto é, gay), tentando ajudar a mãe a pagar as contas. A reflexão surge enquanto a voz poética toma uma "meiota" e fuma uma "sativa". "Autoridades hipócritas" são contrapostas a um "nós" que busca a revolução. A tentativa de construir coletivamente uma vida melhor é dificultada porque "ninguém nota" o que só vira "nota", isto é, as chacinas nos guetos, "o leito que falta no hospita" e a dor sem repercussão social das famílias desamparadas.

Aquelas e aqueles familiarizados com o trabalho de James C. Scott provavelmente concordarão se aproximo o conceito de resistência cotidiana, que o historiador desenvolve em Weapons of the Weak, ao espaço dos saraus, à arte poética de Remido e à de Madame Satã.

A aproximação se aprofunda se levarmos em conta que as "ocupações" a que se refere Madame ocorreram no segundo semestre de 2016 nas escolas secundárias de todo o Brasil, como protesto contra as reformas devastadoras que o governo do então presidente Michel Temer propunha nos meses posteriores ao golpe que destituíra a presidenta Dilma Rousseff.

As ocupações enfrentaram, com estratégias de anonimato e discrição, a fúria da imprensa e de muitos governadores, deputados, prefeitos e vereadores. Nas ocupações das escolas secundárias de Fortaleza, jovens de periferias distantes umas das outras entraram em contato e se tornaram participantes de produções artísticas. Em alguns casos, para financiar a própria subsistência durante a ocupação, estudantes pegavam um ônibus, declamavam poemas e pediam trocados aos passageiros. Quando as ocupações encerraram, Remido e Chris Rodrigues, entre outras e outros poetas dos saraus, encontraram nos ônibus uma forma de divulgar seus poemas e garantir renda. Um novo coletivo, o Sarau da Okupação, surgiu, junto com uma biblioteca comunitária organizada pelo poeta e percusionista, Proletário Baticum. Foi justamente nesse sarau que Madame começou a praticar seus versos entre a poesia e o rap. ${ }^{11}$

Seguindo de perto o argumento de Scott, digamos que as ocupações, pensadas como uma forma de resistir aos cortes no orçamento da educação promovidos pelos governos federal e por diversos governos estaduais em 2016, tornaram-se "uma

11 - A poeta e tradutora Nina Rizzi, muito admirada nos saraus realizados em Fortaleza, publicou dias antes de este artigo ser finalizado, o livro de poemas Sereia no copo d'água. Nele, personagens mulheres apontam as repressões seletivas realizadas por diferentes poderes e que se mostram em violências "interseccionais", intensificadas nos corpos das mulheres negras brasileiras. Uma das poemas (Nina defende que poema é uma palavra feminina), traz os seguintes versos: "esta semana comecei a fazer faxina/ na casa de um senador// me entusiasmo com os tantos cristais/ bibelôs e pratas em que me deter/ tão vagarosamente/ e cada lustre/ cada brilho/ é uma reflexão profunda// e até a dor que sinto na lombar é boa". Sobre o conceito de "repressão seletiva", ver, adiante, a seção "Genocídio cotidiano (I)". Cf. Nina Rizzi, Sereia no copo d'água, São Paulo, Edições Jabuticaba, 2019, p. 18. 
lembrança de resistência e coragem" que deu lastro simbólico a outras formas de resistência cotidiana: saraus, bibliotecas livres, shows, novas ocupações. Essa resistência, como assinala a poesia de Madame, não aparece sequer em nota de jornal. Todavia, ela se alastra pela cidade, constituindo uma força notável que produz novas trajetórias sociais, ou seja: a resistência cotidiana é constituída por formas de reconstruir a existência cotidiana constantemente agredida.

Não há, obviamente, que romantizar os resultados dessa resistência, já que o genocídio cotidiano se reinstitui diariamente, mas ela age e vai se desdobrando em novas formas, numa das cidades mais desiguais no mundo.

Os saraus são muitas vezes interrompidos e, algumas vezes, permanentemente proibidos de acontecer por polícias-milícias e pelas facções. A história da violência policial em Fortaleza precisaria de um capítulo à parte. Contudo, uma breve menção à história das facções, dialeticamente enodada na própria corrupção policial, dá elementos suficientes para a discussão que desejo fazer neste ensaio.

As facções passaram a definir e disputar territórios em Fortaleza a partir de 2014, valendo-se de uma base anterior, formada por gangues e quadrilhas menores. ${ }^{12}$ Paradoxalmente ou não, 2014 é o ano do surgimento de diversos saraus, entre eles o da B1. Nas tensões criadas desde então pela polícia e por facções, bibliotecas comunitárias, formadas pelos participantes dos saraus, precisaram ser fechadas e deslocadas. Um pesquisador do tema, classificou, em 2011, os locais da cidade que seriam anos depois dominados pelas facções, como "territórios de exceção". Neles, raramente assassinatos são investigados e apenas 2,8\% dos homicídios de jovens chegam a um julgamento. A lei se efetiva ali apenas de forma punitiva procurando produzir supostos objetos do Código Penal (CAVALCANTE, 2011). O coletivo que produz o Sarau da B1 relata que dois dos poetas que participaram dos primeiros encontros morreram: uma se suicidou, outro foi vítima de um bloco de madeira mal amparado que o esmagou durante atividades no seu primeiro dia de trabalho. ${ }^{13}$

Sintetizando o que foi posto até aqui: Fortaleza reproduz condições de vida fabulosas para uma pequena fatia de sua população e restringe as condições de vida

12 - O sociólogo Luis Fábio Paiva tem estudado a violência no Ceará há mais de uma década. Para uma sociologia das gangues e das facções em Fortaleza, ver, dele, "Aqui não tem gangue, tem facção: as transformações do crime em Fortaleza, Brasil”, em Caderno CRH, número 32, volume 85, 165-184, 2019. Disponível em https://doi.org/10.9771/ccrh.v32i85.26375.

13 - Samuel Denker organizou uma importante coletânea com os poemas destes primeiros saraus: Sarau da B1 com os poetas de lugar nenhum. Fortaleza: Expressão Gráfica e Editora, 2016. Agradeço a Denker pela gentileza de alcançar ao pesquisador um dos exemplares dessa coletânea. 
nas periferias. Essa restrição das condições de vida é atualmente sentida pela juventude como responsabilidade sobretudo da polícia, disputada também por setores milicianos, e das facções, às quais os setores milicianos da polícia estão ligados. ${ }^{14} \mathrm{O}$ horizonte mais amplo dos conflitos é o tráfico internacional de drogas e de armas, para o qual Fortaleza é um ponto de apoio. Estamos portanto falando de jovens que precisam lidar com o pior do Estado moderno brasileiro (e ocidental), sua face policial assassina e torturadora, e o pior do mercado capitalista mundializado, sua face ligada às guerras pelo monopólio territorial do tráfico de drogas e de armas. ${ }^{15}$ Como diz um poema-dístico de Talles Azigon, poeta, editor, organizador e disseminador de bibliotecas comunitárias,

\section{"Livre mercado}

da morte". ${ }^{16}$

Se governos e mercados reproduzem a restrição das condições de vida de uma fração específica da população de um território, podemos talvez falar em genocídio. Digamos que a produção de mercadorias como armas, drogas, condomínios de luxo e carros blindados tem criado estruturalmente a morte de mil jovens por ano no estado do Ceará. A literatura seria uma das formas de resistência cotidiana articulada pelos jovens das periferias de Fortaleza.

\section{Genocídio cotidiano (I)}

O conceito de genocídio foi cunhado em 1943 por Raphael Lemkin (1944) no contexto das denúncias dos extermínios perpetrados pelos nazistas. O neologismo se

14 - De João Barros, Ricardo Cavalcante e Luís Fábio Paiva, o artigo "Violência no Ceará: as chacinas como expressão da política e do conflito entre facções", publicado em 2019, aborda a correlação entre agentes estatais $\quad \mathrm{e} \quad \mathrm{O} \quad \mathrm{crime} \quad$ organizado. $\quad$ Disponível em http://www.seer.uece.br/?journal=opublicoeoprivado\&page=article\&op=view\&path\%5B\%5D=3405.

15 - Esta síntese se alicerça nos diagnósticos da sua situação social feita pelos participantes dos saraus, conforme pude perceber em conversas ao longo de 2018 e 2019, principalmente no Sarau da B1 e no Sarau da Okupação. As pesquisas feitas por Luís Fernando Souza Benicio, João Paulo Pereira Barros, Jéssica Silva Rodrigues, Dagualberto Barboza da Silva, Camila dos Santos Leonardo e Aldemar Ferreira, divulgadas no artigo "Necropolítica e Pesquisa-Intervenção sobre Homicídios de Adolescentes e Jovens em Fortaleza, Ceará", reforçam a hipótese de que a maneira como os participantes dos saraus entendem a conjuntura social está próxima da maneira como outros jovens moradores das periferias, que não participam dos saraus, entendem a mesma conjuntura. Para eles, a alta taxa de homicídio de jovens nas periferias de Fortaleza decorreria de três fatores: a atividade das facções na tomada de territórios; a política de encarceramento em massa e a "guerra às drogas"; a precarização das políticas sociais. O artigo que sintetiza as pesquisas do grupo acima elencado pode ser acessado em https://dx.doi.org/10.1590/1982-3703000212908.

16 - O dístico está publicado no livro Sara/\#2, de Talles Azigon e Leo Silva, p. 9. 
disseminou ao mesmo tempo em que se disseminavam as grandes revoluções anticoloniais de meados do século XX, sobretudo na África. Já Frantz Fanon (2005) o utilizaria nos seus últimos escritos, no início dos anos 1960, para denunciar as ações do exército francês na Argélia. No Brasil, a palavra, atualmente, está presente em faixas erguidas em passeatas organizadas pelos povos indígenas e pelos diversos movimentos negros. ${ }^{17}$

A discussão a respeito de qual seria a melhor definição para o termo gerou uma literatura a esta altura inabarcável. Vou partir de uma das definições mais recentes: a de Daniel Feierstein, arquitetada para pensar conjuntamente a ditadura militar argentina e a Shoá judaica. De acordo com Feierstein (2014, p.83), uma prática social genocida é uma tecnologia de poder que tem como objetivo a destruição de relações sociais de autonomia e cooperação, além da identidade de uma sociedade, por meio do aniquilamento de uma fração relevante desta sociedade e do uso do terror para estabelecer novas relações sociais e modelos identitários.

A relação entre ditadura militar argentina e chacinas provocadas por policiais no Brasil, e, especialmente na Fortaleza dos anos 2010, aparece de modo explícito no seguinte trecho de um poema sem título de Talles Azigon:

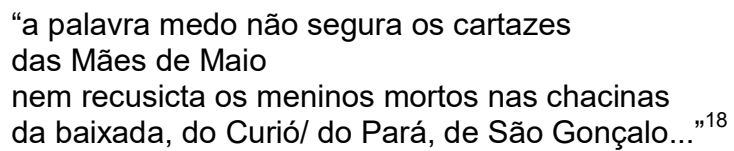

A pesquisa de formas de resistência irmãs tem sido uma constante nos coletivos culturais e saraus constituídos em Fortaleza, a tal ponto que Rômulo Silva, um dos seus principais pesquisadores, pensa neles como uma "rede". ${ }^{19}$ Entre os coletivos entrelaçados aos saraus está o das Mães do Curió, formado pelas mães das 11 pessoas, quase todas jovens, assassinadas por policiais em novembro de 2015. As Mães do Curió buscam referências, entre outros movimentos, no das Mães da Praça

17 - Cf. o livro Sem terra em cartaz, principalmente o capítulo "Violência no campo", em que aparecem vários cartazes feitos pelo Movimento dos Sem Terra em que a denúncia do genocídio está em primeiro plano. O livro foi organizado por Ana Chã, Camilo Álvarez, João Pedro Stedile, Lucimeire Barreto, Marina Tavares, Neuri Rosseto, Rogério Chaves e Vladimir Sachetta. A edição de 2019 é da editora Expressão Popular.

18 - Ver Saral\#2, de Talles Azigon e Leo Silva, p. 57-8.

19 - Essa hipótese está desenvolvida em Rede de afetos: práticas de re-existências poéticas na cidade de Fortaleza, Ceará. Ver nota 2, acima. 
de Maio. Uma das Mães do Curió, Suderly Lima Pereira, costuma afirmar: "Transformei meu luto em luta". ${ }^{20}$

Os coletivos culturais formados nas periferias de Fortaleza estão portanto relendo a história do Brasil e da América Latina, dando a ver uma presentificação de estruturas coloniais, escravistas, imperialistas e ditatoriais na desigualdade social da "redemocratização". Essa presentificação implica assumirmos que o extermínio de povos e a devastação da sua morada comum são projetos acumulados, concentrados e transmitidos pela violenta, injusta e desarrazoada tomada de espaço promovida pela reprodução do "capital-imperialismo". ${ }^{21}$ Contra a continuidade deste projeto de extermínio, executado por meio de "repressões seletivas" os coletivos culturais procuram instalar pequenas ações de resistência, cura, cuidado e proteção mútuas e, nelas, sobreviver. É nesse sentido que o genocídio é cotidiano: ele é contínuo e acumulado. Em termos de projeto social transhistórico, poucas práticas sociais no Brasil têm tanta permanência quanto o genocídio. Neste caso, as tecnologias de poder às quais se refere Feierstein são formadas pela relação dialética entre polícia, facções, mercado mundial e um elemento importante sobre o qual até agora nada tínhamos dito: a mídia local oligárquica complementada e de certo modo aprofundada pelas novas mídias digitais.

As quatro principais emissoras de televisão no Ceará chegam a dedicar 19 horas e 50 minutos por dia para os chamados "programas policialescos". É uma grande quantidade de discursos genocidas repetidos sem parar, criminosa e impunemente. Na manhã seguinte à Chacina da Messejana (que provocou a origem do coletivo das Mães do Curió), em 12 de novembro de 2015, um apresentador de televisão com mandato parlamentar afirmou sobre os mortos: "São onze almas sebosas a menos". 22

20 - A respeito das "Mães do Curió", ver, de Indra Lucena Arnaud Paiva, Isabel Aline Pinho Romão, Mayrla Stefani Oliveira Fernandes e Raul da Fonseca Silva Thé, "De repente pranto fez-se a luta", na revista Direitos humanos e educação, n. 1, v. 2, janeiro a junho de 2019, p. 47 a 59 . Ver também o artigo "Juntas (os) somos mais fortes: resistências afetivas e emoções politicas", de Leila Maria Passos de Souza Bezerra, Ingrid Lorena Silva Leite, disponível em https://periodicos.ufpel.edu.br/ojs2/index.php/expressaextensao/article/view/17233/pdf.

21 - Capital-imperialismo, conceito que utilizo neste momento do ensaio, e repressão seletiva, que aparecerá logo em seguida, são conceitos propostos no clássico livro da historiadora Virgínia Fontes, $O$ Brasil e o capital-imperialismo. Vou deixar para outro artigo uma análise mais demorada dos argumentos de Fontes e da pertinência de utilizá-los para pensar as ações dos coletivos culturais de Fortaleza. Cf. Virgínia Fontes, O Brasil e o capital-imperialista: teoria e história, Rio de Janeiro, UFRJ, 2010, principalmente p. 226 e seguintes, p. 318 e seguintes.

22 - Todos os dados utilizados neste e no próximo parágrafo constam no relatório final do "Comitê Cearense pela Prevenção de Homicídios na Adolescência”, 2016, p. 317 e seguintes. 
Muitas vezes, os programas de televisão culpam pelas mortes os próprios pais dos meninos e meninas assassinados. Em março de 2015, a Agência de Notícias dos Direitos da Infância pesquisou 28 programas de televisão policialescos transmitidos em diversas capitais brasileiras. Encontrou mais de 22 mil violações, infrações e descumprimentos de leis, normas, direitos e tratados. Ao recortar e analisar 1.928 narrativas verificou que todas elas desrespeitavam o Código de Ética dos Jornalistas. Essa situação ganhou novas dimensões igualmente criminosas com as mídias digitais, em que vídeos como os de Dandara sendo espancada e morta se disseminam rapidamente a partir de redes de desinformação financiadas por empresários e políticos $^{23}$.

Tais programas e mídias desrespeitam a lei a todo segundo. Sempre ao final de cada reportagem, os programas televisivos informam se o adolescente morto tinha ou não tinha antecedentes criminais. Caso tivesse, o telespectador interpreta o assassinato como algo legítimo, merecido pela vítima e até mesmo provocado por ela.

\section{Totalitarismo institucional}

Nesse ponto gostaria de abrir uma discussão que se vale do que o escritor e jornalista Bernardo Kucinski (2014, p. 166 em diante) denominou "totalitarismo institucional", em $K$ : relato de uma busca. Este romance, publicado pela primeira vez em 2011, narra do ponto de vista de um pai, em primeira pessoa, o desaparecimento de uma filha, Ana Rosa Kucinski, durante a ditadura civil-militar brasileira. O enredo acompanha a passagem no pai de uma culpa ensimesmada e dolorida para uma culpa socializada em interpelações coletivas ao poder. Tais interpelações acontecem inclusive na forma da narrativa literária não-ficcional que estamos lendo, em que, como diz o escritor, tudo é invenção, mas quase tudo aconteceu (KUCINSKI, 2014, p. 8). Essa trama com desfecho aparentemente esperançoso - a construção ainda que tardia de uma reflexão coletiva sobre a ditadura civil-militar brasileira - encerra a revelação de um subtexto: o sistema repressivo montado durante a ditadura continuava estruturado e ativo em 2010 , quando distribuía pistas falsas e confundia as famílias que tentavam fazer o luto de seus mortos.

23 - Dandara é um nome simbólico no Brasil, remetendo à Dandara dos Palmares, líder negra do Quilombo dos Palmares que, para diversos movimentos negros, simboliza o início da verdadeira democracia brasileira, que nunca se realizou. Dandara teria se suicidado durante a invasão do Quilombo, no final do século XVII. Em 15 de fevereiro de 2017, Dandara dos Santos foi espancada e assassinada sob tortura em Fortaleza. Travesti, Dandara provocou a ira de alguns homens. As cenas de tortura foram filmadas nos celulares e rapidamente disponibilizadas em redes sociais. 
Para reforçar esse contraponto, Kucinski (2014, p. 169) fez seu narrador escrever um pequeno ensaio, que suspende a narrativa para explicar a ideia de um totalitarismo institucional. Kafka, diz neste ensaio o narrador, teria ficcionalizado em sua prosa os mecanismos de culpa e dívida do "totalitarismo familiar", alegoria do totalitarismo mais amplo, que se desenhava na Europa. Já "o 'totalitarismo institucional' exige que a culpa, alimentada pela dúvida e opacidade dos segredos, e reforçada pelo recebimento das indenizações, permaneça dentro de cada sobrevivente como drama pessoal e familiar e não como tragédia coletiva que foi e continua sendo, meio século depois". Assim, a própria possibilidade de alegorizar em termos públicos a tragédia pretensamente individual encontra limites objetivos.

Os coletivos culturais da juventude de Fortaleza analisam constantemente os mecanismos desse totalitarismo institucional. A culpa, a dúvida, os segredos tendem a ficar restritos como drama pessoal e familiar, do qual o suposto culpado seria o jovem assassinado e/ou torturado. Surge daí a necessidade de pensar a dor individual como uma tragédia coletiva, que deve, portanto, ser elaborada literalmente em praça pública, diante do microfone aberto (o luto é luta, como afirma Suderly). Esse ato de coragem e desrecalque acaba dando a ver o que há de comum ao projeto de tomada de corpos e terras alicerçado pelo "capital-imperialismo".

Kucinski - por meio de seu narrador - percebeu que em 2010 os aparelhos repressores da tortura e do assassinato ditatoriais continuavam funcionando. Em 1998, no disco, Sobrevivendo no inferno, os Racionais MCs reconheceram no massacre do Carandiru, em que, em 1992, pelo menos 111 pessoas foram assassinadas pela polícia, a verdade do Estado brasileiro. ${ }^{24}$ Colonialismo, escravidão, ditaduras e desigualdade racista se coordenaram, por assim dizer, didaticamente, exigindo ou até mesmo tornando incontornável uma retomada crítica da história cultural brasileira em que o genocídio é desvendado como epistemologia encobridora, que foraclui seus fundamentos. Canudos, Carajás, Carandiru, Curió seriam, nesse sentido, os centros simbólicos (ou não simbolizados, ou foracluídos) da República e, ao serem pensados como "totalitarismo institucional", revelariam a estruturação genocida do Estado brasileiro a serviço da grande propriedade de terras e do capital financeiro.

24 - Ver o prefácio de Acuam Silvério de Oliveira para o livro dos Racionais MCs, Sobrevivendo no inferno. São Paulo: Cia. das Letras, 2018, p. 36. 


\section{Ocupar, resistir}

Podemos dizer então que as condições de disseminação do poema "Literatura te tira do tiro da viatura" se configuraram em um processo coletivo de resistência cotidiana contra o genocídio cotidiano, o genocídio que se reinstala numa repetição patológica da cena de assassinato do "outro" social do latifundiário e do controlador dos grandes capitais. Essa cena imaginária - mas nem por isso menos objetiva - em que o Brasil fuzila todos os pobres e assim resolve seus dilemas sócio-econômicos fez recentemente um dos nós da campanha do atual presidente, Jair Bolsonaro.

Para sintetizar, digamos que genocídio cotidiano, totalitarismo institucional e mercado da morte perfazem uma constelação de práticas contra as quais a literatura dos coletivos culturais procura opor outras práticas e representações. Enquanto o genocídio nega os fatos; enquanto o totalitarismo individualiza culpas e responsabilidades; e enquanto o mercado da morte romantiza e torna o assassinato entretenimento midiático; os poemas produzidos pelos coletivos culturais desvelam a relação do poder econômico e político com as mortes e o sofrimento. A palavra que nega, justifica, encobre, hierarquiza e classifica o sofrimento do outro é deslocada para que um novo espaço simbólico surja, mais arejado pelo cuidar, curar, acolher, solidarizar, ocupar, afetar a si e ao outro.

A reflexão social coletiva sobre os destinos da comunidade frente ao reconhecimento da persistência do genocídio como projeto de mercado e de Estado caracteriza os pequenos coletivos culturais insurgentes que se disseminaram em Fortaleza principalmente depois da expansão das facções - que data de 2014 - e das milícias, e, sobretudo, depois das ocupações das escolas secundaristas, no final de 2016. Literatura te tira do tiro da viatura sintetiza portanto esse anseio, dando-lhe uma forma literária, entre o conselho e a profecia.

\section{Excurso: genocídio cotidiano (II)}

De acordo com Rômulo Silva, alguns dos temas mais presentes nos poemas declamados nos saraus são: o racismo institucionalizado, as frequentes abordagens da Polícia Militar ou da Guarda Municipal, a escola como local de agressão e humilhação, o vínculo desfeito com pais mortos ou dependentes químicos, a violência doméstica, o tráfico de drogas, o abandono, a situação de rua, as medidas 
socioeducativas, a criminalização e o sentimento de inferioridade (SILVA, 2014, p. 166,68 e 105).

Os poemas ditos nos saraus teriam o objetivo de criar palavras que cuidem das pessoas atingidas pelo genocídio cotidiano, disseminando relatos para o que permanece "indizível" ou difícil de ser expresso.

Nas "Conferências introdutórias à psicanálise", proferidas em 1916 e 1917, período de recrudescimento da primeira Guerra Mundial, Freud ressaltou que uma das bases da neurose traumática seria a fixação do sujeito no acidente sofrido, um retorno de todo coração à situação traumática tal como trazida pela memória. ${ }^{25}$ No caso que temos em foco, não é apenas o sujeito que volta à situação traumática, mas é a situação traumática que ocupa continuamente o sujeito.

Para Freud, quem sentiu um trauma vive a cena do trauma considerando-a no tempo presente. Também durante a primeira guerra mundial, ele escreveu seu tocante ensaio sobre a transitoriedade, perguntado-se o que acontece com a capacidade de amar quando os objetos de amor são abruptamente retirados do eu. Enquanto, para o Freud desse período de guerra, os bens culturais teriam certa permanência e seriam reconstruídos em bases mais sólidas depois da guerra, para os jovens das periferias de Fortaleza o genocídio tem permanência e precisa ser interrompido pelos bens culturais. A cultura é impermanente e frágil. O genocídio, cotidiano.

Em outras palavras, a situação traumática não cessa de ocorrer, cotidianamente. Esse não cessar ocorre desde fora do sujeito, trazido pela polícia, pelo Estado, pelas milícias, pelas facções, pelo mercado, pela mídia, em outras palavras, pela expansão do aparato que estrutura a tomada de terras e corpos para a reprodução do capitalismo financeiro internacional sob dois de seus principais negócios, o tráfico de armas e o tráfico de drogas. Do ponto de vista do sujeito, não há tempo para que a situação traumática seja recalcada e, mais tarde, os afetos por ela suscitados se desloquem para outras representações ou gestos. A situação traumática não cessa de acontecer à luz do dia. Ocupar, resistir, re(existir), tomar a palavra se tornam questão de vida ou morte.

É por isso que, do ponto de vista da teoria da literatura, importa ver como as "pequenas tradições" se apropriam da literatura, desde já, um instrumento das "grandes tradições", no sentido que James C. Scott $(1985,1990)$ dá a estes termos.

25 - Ver Lecciones introductorias al psicoanalisis, em Obras completas, tomo II, tradução de Luiz LopezBallesteros y Torres, Biblioteca Nueva. Para a referência a seguir, a respeito da transitoriedade, ver, no mesmo tomo, o ensaio "Lo perecedero". 
Porque é instituindo a resistência da arte que os poetas dos saraus constroem suas artes da resistência.

A literatura foi muitas vezes definida, a partir do formalismo russo, como uma forma de estranhamento da palavra cotidiana. ${ }^{26}$ Ao longo deste ensaio em que tentei compreender aspectos da literatura produzida nos saraus e coletivos culturais de Fortaleza, reuni elementos que me permitem, uma vez que fui educado pela potência da práxis dos saraus, reformular da seguinte maneira esse conceito: literatura nas periferias de Fortaleza é a palavra pública que suspende o genocídio cotidiano. Com ela, os jovens artistas resistem aos movimentos da guerra perpétua.

\section{Referências Bibliográficas}

CAVALCANTE, R. M. B., Vidas breves: Investigaçãoacerca do assassinato de jovensem Fortaleza (dissertação de mestrado). Programa de PósgraduaçãoemPolíticasPúblicas e Sociedade, UniversidadeEstadual do Ceará, Fortaleza, CE, Brasil, 2011.

FANON, Frantz. Oscondenados da terra, tradução de ElnilceAlbergaria Rocha e Lucy Magalhães. Juiz de Fora: Ed. UFJF, 2005.

FEIERSTEIN, Daniel. El genocidiocomopráctica social: entre el nazismo y la experienciaargentina (hacia un análisis del aniquilamentocomoreorganizador de las relacionessociales), Buenos Aires, Fondo de CulturaEconómica, 2014.

KUCINSKI, Bernardo, K. relato de umabusca. São Paulo: Cosac\&Naif, 2014

LEMKIN, Raphael Rule in Occupied Europe. Washington: Carnegie Endowment for International Peace, Division of International Law, 1944.

SCOTT, James C. Domination and the Arts of Resistence. New Haven: Yale, 1990.

SCOTT, James C. Weapons of the Weak: Everyday forms of Peasant Resistence. New Haven: Yale, 1985

SILVA, FRANCISCO RÔMULO DO NASCIMENTO. REDE DE AFETOS: PRÁTICAS DE RE-EXISTÊNCIAS POÉTICAS NA CIDADE DE FORTALEZA (CE. 2014. $212 \mathrm{f}$. Dissertação (Mestrado Acadêmico ou Profissional em 2014) - Universidade Estadual do Ceará, $2014 . \quad$ Disponível em: <http://siduece.uece.br/siduece/trabalhoAcademicoPublico.jsf?id=87392> Acesso em: 4 de janeiro de 2021.

26 - Cf. Tzvetan Todorov, Teoria da literatura: textos dos formalistas russos. São Paulo: Unesp, 2013, principalmente os ensaios "A arte como procedimento", "Do realismo da arte", de Victor Chklóvski e Roman Jakobson. 